\title{
Noninvasive Ventilation for Post-Pneumonectomy Severe Hypoxemia
}

\author{
Charilaos-Panagiotis C Koutsogiannidis MD, Fotini C Ampatzidou MD, Olga G Ananiadou MD, \\ Theodoros E Karaiskos MD, and George E Drossos MD
}

\begin{abstract}
ARDS remains a lethal complication after major lung resections. The reported mortality ranges from $50 \%$ to $100 \%$, with increased incidence and mortality rates in pneumonectomy patients. The pathogenesis of early ARDS is still not fully understood, and the majority of patients will require mechanical ventilation. A review of the literature reveals that the role of noninvasive ventilation (NIV) in ARDS after lung resection is unclear, in contrast to its well established benefits in other types of respiratory failure. NIV is a technique of augmenting alveolar ventilation delivered by face mask, without introducing an endotracheal tube. NIV may reduce the need for endotracheal mechanical ventilation and improve clinical outcome in patients with acute respiratory failure after lung resection, avoiding complications related to intubation. We present a case of early ARDS following left-sided pneumonectomy, where bi-level positive airway pressure ventilation prompted a successful outcome. Key words: ARDS; post-pneumonectomy edema; post-pneumonectomy lung injury; acute respiratory failure; noninvasive ventilation; bi-level positive airway pressure; endotracheal intubation; mechanical ventilation. [Respir Care 2012;57(9):1514-1516. ( 2012 Daedalus Enterprises]
\end{abstract}

\section{Introduction}

Despite improvements in patient selection and in surgical, anesthetic, and critical care management, lung injury remains a leading cause of death from major pulmonary resection. ${ }^{1}$ This complication has most commonly been described after pneumonectomy, ${ }^{2}$ with a range of reported incidence, due to variability in lung injury definition. ${ }^{1}$

The incidence of ARDS, the most severe form of lung injury, after lung resection is $2-5 \%$, and post-pneumonectomy increases the occurrence up to $4-15 \% .^{1-4}$ Patients with ARDS require ventilatory assistance, usually escalating to endotracheal intubation and mechanical ventilation (ETMV), which is associated with increased mortality rate.

The authors are affiliated with the Cardiothoracic Surgery Department, General Hospital G Papanikolaou, Thessaloniki, Greece; with the exception of Dr Ampatzidou, who is affiliated with the Second ICU Department at that institution.

The authors have disclosed no conflicts of interest.

Correspondence: Charilaos-Panagiotis C Koutsogiannidis MD, Cardiothoracic Surgery Department, General Hospital G Papanikolaou, Exohi 57010, Thessaloniki Greece. E-mail: harisdoc76@yahoo.gr.

DOI: $10.4187 /$ respcare.01493
Noninvasive ventilation (NIV) is an effective technique of augmenting alveolar ventilation delivered by face mask, for improving gas exchange and avoiding ETMV, in selected patients with acute respiratory failure (ARF). The highest success rates are recorded in patients with exacerbation of COPD, particularly in patients presenting primarily with hypercarbic ARF. ${ }^{5}$ Success has been more limited in hypoxemic ARF, ${ }^{5}$ and there are only few reports of NIV on ARDS. ${ }^{6,7}$ Even though data exist on NIV in ARF after lung resection, it is not clear whether all cases meet the criteria of the American-European consensus conference on ARDS. ${ }^{8}$

We report a case of early ARDS after left-sided pneumonectomy treated successfully with noninvasive bi-level positive airway pressure (BPAP).

\section{Case Report}

A 75-year-old male was referred to our department suffering from $\mathrm{T}_{2} \mathrm{~N}_{2} \mathrm{M}_{0}$ squamous cell lung cancer. He was a smoker with history of hypertension and negative cardiac diagnostic studies. Preoperative spirometry values were $\mathrm{FEV}_{1} 2.17 \mathrm{~L}$ (81\% of predicted) and FVC $3.21 \mathrm{~L}$ (90\% of predicted), whereas the predicted postoperative $\mathrm{FEV}_{1}$ was 1.2 L. The patient underwent an uncomplicated left-sided pneumonectomy, and postoperatively was mechanically 


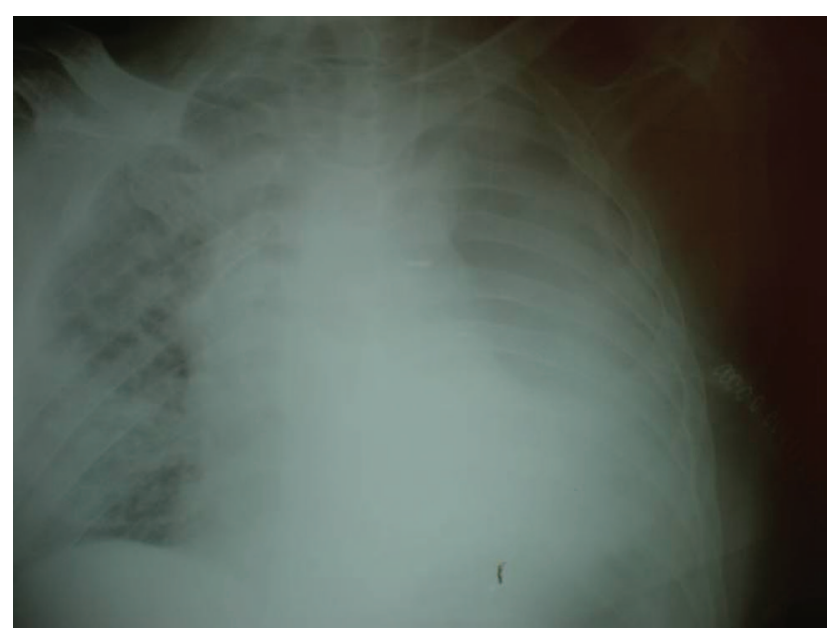

Fig. 1. Chest radiograph at the second postoperative day shows the global infiltrates of the right lung.

ventilated for 6 hours, with no need of perioperative blood transfusion. On the first postoperative day he was transferred to the high dependence unit, hemodynamically stable, with negative fluid balance, breathing comfortably, on $4 \mathrm{~L} / \mathrm{min}$ oxygen delivered through nasal cannula.

On the second postoperative day he became acutely short of breath, and, despite treatment with diuresis and administration of nebulized bronchodilators and intravenous corticosteroids, there was a dramatic decrease of oxygen saturation (to 85\%) and need for increased oxygen delivery through non-rebreathing mask at $15 \mathrm{~L} / \mathrm{min}$. Arterial blood gas analysis showed severe hypoxemia: $\mathrm{pH} 7.30$, $\mathrm{P}_{\mathrm{O}_{2}} 60 \mathrm{~mm} \mathrm{Hg}, \mathrm{P}_{\mathrm{CO}_{2}} 50 \mathrm{~mm} \mathrm{Hg}, \mathrm{HCO}_{3}{ }^{-} 25 \mathrm{mEq} / \mathrm{L}$. His dyspnea quickly worsened, with respiratory rate of 35 breaths/min and active contraction of accessory respiratory muscles. The chest radiograph also revealed global infiltrates of the right lung (Fig. 1). The patient was apyrexial, with negative inflammatory markers. A bedside 2-dimensional echocardiography showed good left ventricular function, no diastolic dysfunction, and systolic pulmonary arterial pressure at $45 \mathrm{~mm} \mathrm{Hg}$.

BPAP was applied on spontaneous mode via full face mask; the ventilation support system used was a Vector Bilevel ST20 (Hoffrichter, Schwerin, Germany). The initial inspiratory positive airway pressure to achieve patient comfort was set at $18 \mathrm{~cm} \mathrm{H}_{2} \mathrm{O}$, and expiratory positive airway pressure was at $6 \mathrm{~cm} \mathrm{H}_{2} \mathrm{O}$, with high flow oxygen $(15 \mathrm{~L} / \mathrm{min})$ to obtain percutaneous oxygen saturation above $90 \%$. The head of the bed was kept elevated at a $45^{\circ}$ angle to minimize the risk of aspiration. Within the first 2 hours of BPAP, arterial blood gas analysis showed substantial improvement: $\mathrm{pH}$ 7.41, $\mathrm{P}_{\mathrm{O}_{2}} 130 \mathrm{~mm} \mathrm{Hg}, \mathrm{P}_{\mathrm{CO}_{2}} 42 \mathrm{~mm} \mathrm{Hg}$, $\mathrm{HCO}_{3}{ }^{-} 24 \mathrm{mEq} / \mathrm{L}$. For 2 days BPAP was given continuously, with decreased inspiratory pressure, to $16 \mathrm{~cm} \mathrm{H}_{2} \mathrm{O}$, and oxygen flow at $12 \mathrm{~L} / \mathrm{min}$, and for the next 3 days

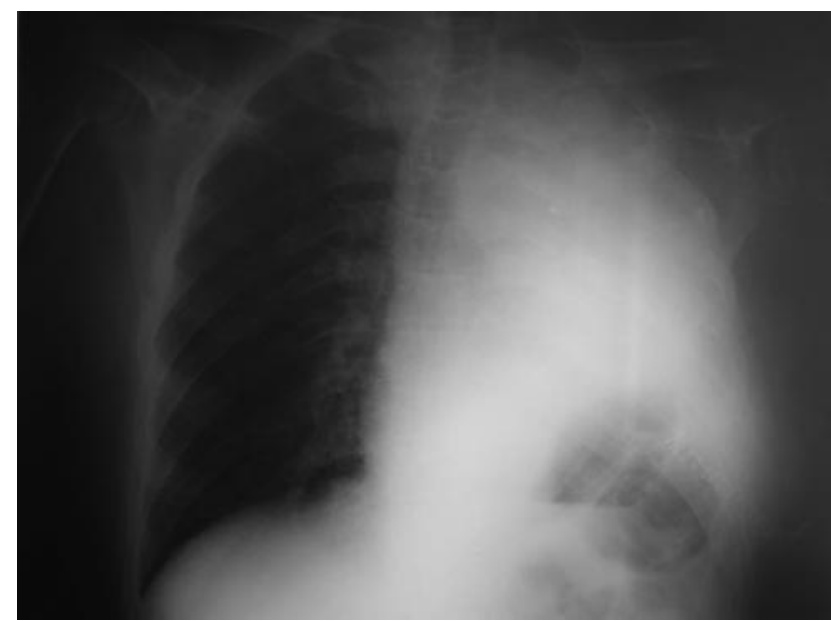

Fig. 2. Chest radiograph before discharge shows that imaging findings have improved.

intermittently, with lowered oxygen flow at $10 \mathrm{~L} / \mathrm{min}$, depending on response and for reduced duration. Our patient was gradually able to tolerate several daily chest physiotherapy sessions with physical manipulations and breathing techniques. On the next 4 days oxygen delivery was provided only through a simple mask at $8-10 \mathrm{~L} / \mathrm{min}$, and for the last 2 days intermittently through a nasal cannula at $4 \mathrm{~L} / \mathrm{min}$. Even though symptoms were attenuated in the first 3 days, radiographic findings were evident for more than 5 days. Radiographic findings were gradually improved, and the patient also had negative sputum cultures and remained apyrexial. The patient was discharged on postoperative day 14 without need of supplemental oxygen therapy. The chest radiograph at discharge had normal post-pneumonectomy findings (Fig. 2).

\section{Discussion}

Post-pneumonectomy lung injury is a clinical entity that is difficult to manage and is associated with substantial mortality. In our case, the patient met the criteria of the American-European consensus conference on ARDS, which include acute clinical onset, $\mathrm{P}_{\mathrm{O}_{2}} / \mathrm{F}_{\mathrm{IO}_{2}}<200 \mathrm{~mm} \mathrm{Hg}$, acute pulmonary infiltrates on frontal chest radiograph, and absence of signs of left cardiac failure. ${ }^{8}$ Echocardiography was the only safe and reliably applied method to assess the hemodynamic profile of our patient, since SwanGanz catheterization in pneumonectomy patients can be hazardous and also may provide misleading values of left atrial pressure. ${ }^{9}$ The development of ARDS has been associated with certain perioperative risk factors such as excessive fluid administration, inappropriate ventilatory settings, and large surgical times. ${ }^{1-3}$ Available data also suggest that decreased postoperative predicted lung function, as in our case, is an independent risk factor. ${ }^{3}$ 


\section{Noninvasive Ventilation for Post-Pneumonectomy Severe Hypoxemia}

The main objective of using NIV as a first-line intervention in our patient was to avoid ETMV and subsequent complications. A recent prospective study and retrospective evaluations of lung resection patients who required ETMV found mortality rates ranging from $67 \%$ to $80 \% .^{10}$ However, although the use of NIV is well established in ARF of non-surgical origin, data on efficacy in ARDS, especially following major thoracic resections, are limited. In everyday clinical practice of centers expert on NIV, no more than $31 \%$ of patients with ARDS are treated with NIV. ${ }^{7}$ In a comparative study on conservative treatment with and without NIV in acute hypoxemic respiratory insufficiency following lung resection, provision of NIV decreased the rate of ETMV from $50 \%$ to $20.8 \%$, and inhospital mortality from $37.5 \%$ to $12.5 \% .^{10}$ Of course, 2 observational NIV studies reported an intubation rate of $50 \%$, which was similar in ARDS of pulmonary or extrapulmonary origin. ${ }^{6,7}$ It has also been reported that strong predictive factors associated with NIV failure are previous cardiac comorbidities and no initial response to NIV. The high severity scores and the inability to improve $\mathrm{P}_{\mathrm{O}_{2}} / \mathrm{F}_{\mathrm{IO}_{2}}$ after the first hour of NIV in ARDS were independently associated with NIV failure. ${ }^{7,11}$

Despite concerns about the early use of NIV after lung resection, because it may negatively interfere with pleural leaks, ${ }^{12}$ our patient had a further uncomplicated postoperative course, with no NIV-related adverse outcome.

Studies on NIV with different interfaces suggest that mask tolerance may play a role in the success rate, with an almost full-day dependence on ventilatory support. ${ }^{13} \mathrm{We}$ feel that most patients can tolerate oronasal mask, as delivered in our patient, with the need of slight sedative administration, should the occasion arise. Another issue is the fact that our patient was manipulated in a high dependence unit with a ventilation support system, without oxygen blender. In this setting of severe post-pneumonectomy hypoxemia, the $\mathrm{F}_{\mathrm{IO}_{2}}$ delivered was not stable and was titrated based only on pulse oximetry. ${ }^{14}$

Despite the age of our patient, the initial need for high levels of pressure and longer duration for weaning due to compromised respiratory compliance, NIV was well tolerated and proven to be safe and effective. However, experience with NIV for this ARF etiology is less extensive.
Therefore, management in an ICU with ready availability of intubation in case of failure is strongly recommended.

\section{REFERENCES}

1. Kutlu CA, Williams EA, Evans TW, Pastorino U, Goldstraw P. Acute lung injury and acute respiratory distress syndrome after pulmonary resection. Ann Thorac Surg 2000;69(2):376-380.

2. Parquin F, Marchal M, Mehiri S, Hevré P, Lescot B. Post-pneumonectomy pulmonary edema: analysis and risk factors. Eur J Cardiothorac Surg 1996;10(11):929-933.

3. Alam N, Park BJ, Wilton A, Seshan VE, Bains MS, Downey RJ, et al. Incidence and risk factors for lung injury after lung cancer resection. Ann Thorac Surg 2007;84(4):1085-1091.

4. Tang SSK, Redmond K, Griffiths M, Ladas G, Goldstraw P, Dusmet M. The mortality from acute respiratory distress syndrome after pulmonary resection is reducing: a 10-year single institutional experience. Eur J Cardiothorac Surg 2008;34(4):898-902.

5. Hess DR. The evidence for noninvasive positive-pressure ventilation in the care of patients in acute respiratory failure: a systematic review of the literature. Respir Care 2004;49(7):810-829.

6. Rocker GM, Mackenzie MG, Williams B, Logan PM. Non-invasive positive pressure ventilation: successful outcome in patients with acute lung injury/ARDS. Chest 1999;115(1):173-177.

7. Antonelli M, Conti G, Esquinas A, Montini L, Maggiore SM, Bello $\mathrm{G}$, et al. A multiple-center survey on the use in clinical practice of noninvasive ventilation as a first-line intervention for acute respiratory distress syndrome. Crit Care Med 2007;35(1):18-25.

8. Bernard GR, Artigas A, Brigham KL, Carlet J, Falke K, Hudson L, et al. The American-European consensus conference on ARDS. Definitions, mechanisms, relevant outcomes and clinical trial coordination. Am J Respir Crit Care Med 1994;149(3 Pt 1):818-824.

9. Wittnich C, Trudel J, Zidulka A, Chiu RC. Misleading "pulmonary wedge pressure" after pneumonectomy: its importance in postoperative fluid therapy. Ann Thorac Surg 1986;42(2):192-196.

10. Auriant I, Jallot A, Herve P, Cerrina J, Le Roy Ladurie F, Fournier $\mathrm{JL}$, et al. Noninvasive ventilation reduces mortality in acute respiratory failure following lung resection. Am J Respir Crit Care Med 2001;164(7):1231-1235.

11. Lefebvre A, Lorut C, Alifano M, Dermine H, Roche N, Gauzit R, et al. Noninvasive ventilation for acute respiratory failure after lung resection: an observational study. Intensive Care Med 2009;35(4): 663-670.

12. Aguiló R, Togores B, Pons S, Rubí M, Barbé F, Agustí AG. Noninvasive ventilatory support after lung resectional surgery. Chest 1997;112(1):117-121.

13. Conti G, Cavaliere F, Costa R, Craba A, Catarci S, Festa V, et al. Noninvasive positive pressure ventilation with different interfaces in patients with respiratory failure after abdominal surgery: a matchedcontrol study. Respir Care 2007;52(11):1463-1471.

14. Crimi C, Noto A, Princi P, Esquinas A, Nava S. A European survey of noninvasive ventilation practices. Eur Respir J 2010;36(2):362369. 